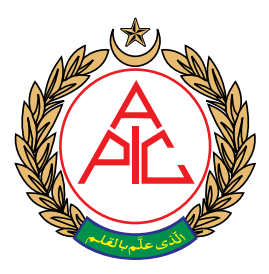

${ }^{1} \mathrm{PhD}$ Scholar, Institute of Clinical Psychology, University of Management and Technology, Lahore; lamae09@gmail.com ${ }^{2}$ Assistant Professor, Institute of Clinical Psychology, University of Management and Technology, Lahore; muhammad.rafiq@umt. edu.pk

Correspondence: Lamae

Zulfiqar, PhD Scholar, Institute of Clinical Psychology, University of Management and Technology, Lahore; lamae09@gmail.com Received: 03 February 2020; Reviewed: 7 March 2020; Revised: 11 March 2020;

Accepted: 12 March 2020

\title{
Exploring experiences and coping strategies of nurses working in intensive care unit: A qualitative study
}

\author{
Lamae Zulfiqar ${ }^{1}$, Muhammad Rafiq, $\mathrm{PhD}^{2}$
}

\begin{abstract}
Background: The nursing profession is in its developing stages in the country yet when it comes to the work itself, the environment can be very competitive. Though nurses, in general, go through a tough time, it is the intensive care unit (ICU) nurses who have to be on their toes all the time. Those working in the pediatric department, deal with young patients requiring constant supervision and care compared to other ICUs.

The aim of the current project was to explore the experiences and coping strategies of nurses working in pediatric ICUs in a public sector hospital of Lahore, Pakistan.

Methodology: Semi structured in-depth interviews were conducted with 5 nurses who were working in pediatric ICU (PICU) in a public sector hospital. All the nurses were female.

Results: The data was managed and analyzed using NVivo 12 version. The four superordinate themes, e.g. vocational problems, psychological problems, biosocial problems and coping had 11 master themes and 70 sub themes.

Conclusion: Nurses in PICU face a lot of problems in their everyday work life, yet they have found their own ways to cope with their stress. Regardless the shortage of staff and constant complaints against them, nurses of PICU find solace in religious coping and socialization (as much as they can get). These results will help authorities to look into the problems and provide suitable solutions.
\end{abstract}

Key words: Pediatric intensive care unit; nurses; Stress; Hospital, Public sector; Coping; Phenomenology

Citation: Zulfiqar L, Rafiq M. Exploring experiences and coping strategies of nurses working in intensive care unit: A qualitative study. Anaesth Pain Intensive Care 2020;24(1):42-49. DOI: https://doi.org/10.35975/apic.v24i1.1223

\section{INTRODUCTION}

The healthcare system of Pakistan has always remained questionable when it comes to available facilities, quality of education and planning for future development. Pakistan, so far, has produced little fundamental change in its healthcare sector given the perpetual economic crisis. ${ }^{1}$ One of these deep seated problems has been the lack of due recognition of nursing profession, which led to poor focus on the training and education of nurses in the country. Previously, it was easier to become a nurse in Pakistan by getting a 3 year diploma; but now you need to go through graduate level of education to qualify to become a nurse. By 2020, it is envisioned by PNC (Pakistan Nursing Council) that to qualify to practice, nurses would be required to do graduation (Bachelor of Science in Nursing Education $\mathrm{BScN}$ ) and they would also be awarded licenses. ${ }^{2}$

The nurses work in almost every department of the hospital, yet the ones who are the most stressed are the intensive care unit (ICU) nurses. ${ }^{3}$ These nurses 
have to remain alert all the time and are responsible for every patient under their care and in critical condition. ${ }^{4}$ Out of these the pediatric intensive care unit (PICU) is much more stressful, as children are unable to take care of themselves, have no familiar face around and are difficult to soothe. The PICU gets even more stressful for a nurse because the nurse has to deal with the child and the medical treatment at the same time. The nursing staff might remain focused on the diagnosis and treatment of the child's illness and not on the assessment of the child and the family's expectations, values, and understanding of the medical implications of the illness. ${ }^{5}$ All of these factors pose competing demands to the staff.

This study aimed to understand the experiences of PICU nurses, the problems they face and how they cope with these problems.

What would be the stress producing factors for a nurse working in PICU?

What are the various strategies adopted by PICU nurses to cope with their problems?

We aimed to present a mind map for comparison with the emerged model.

\section{METHODOLOGY}

Research design: Phenomenology was used as a research design.

Sampling: Purposive sampling was employed. Only those nurses were included who (1) worked in PICUs and (2) nurses of public sector hospital were recruited only.

Sample: The sample comprised of 5 nurses who worked in a PICU of a public sector hospital in Lahore, Pakistan. Initially, 13 nurses were approached out of which only 5 agreed to participate in the study.

Procedure: Formal permission was taken from the Medical Superintendent of the public sector hospital and the pediatric department to conduct interviews with nurses. The nurses were approached and explained the nature of study. In depth interviews were conducted with each nurse and ambiguities were clarified by interviewer for interviewee and vice versa. These interviews were only a onetime interview and were audio recorded. The interviews lasted approximately $20 \mathrm{~min}$. Anonymity of the participants and confidentiality of the data was ensured. Participants were given a choice of withdrawal at any time of the study.

\section{Data Analysis and Results}

Although no gender discrimination was made while determining the sampling criteria, yet only female nurses were part of the sample eventually. The interviews were transcribed from Urdu language to English language. The data weremanaged and analyzed using NVivo 12 version. The interviews were coded and subthemes, master themes and superordinate themes were generated. Four superordinate themes were vocational problems, psychological problems, biosocial problems and coping and 11 master themes and 70 subthemes emerged. The final emerged model consisting of superordinate themes and their master themes is shown in Figure 2. A summary of all themes is also provided in Table 1.

\section{PSYCHOLOGICAL PROBLEMS}

The superordinate theme of psychological problems was comprised of four master themes namely; antipathy, burnout, low self-worth, and consternation. Each of these master themes comprised of sub themes. Figure 3 depicts the model for the psychological problems theme.

Antipathy: The nurses reported that they get in a tiff with the attendants which makes them grumpy and irritated throughout the day. They also said that if there is a complaint against them and they are not given a chance to explain themselves, they either confront their seniors or avoid the person altogether. One of them said "if a person works more than his capacity she will become irritated obviously". Another one reported that "There are a lot of issues...sometimes we complain to the head nurse when she favors doctors over us". It was reported that it is mostly the shortage of staff that causes anger "When there in shortage of staff then we feel angry that... why is there shortage? If there were more people then we could manage better".

Burnout: Stress was reported to be the main problem being faced by nurses every single day. This was because of the excessive work load and limited
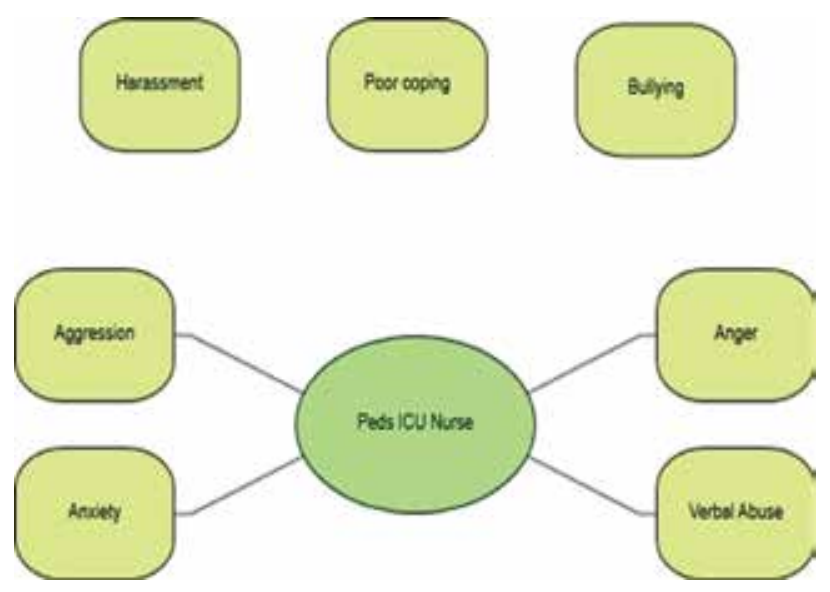

Figure 1: Mind map of the current project 


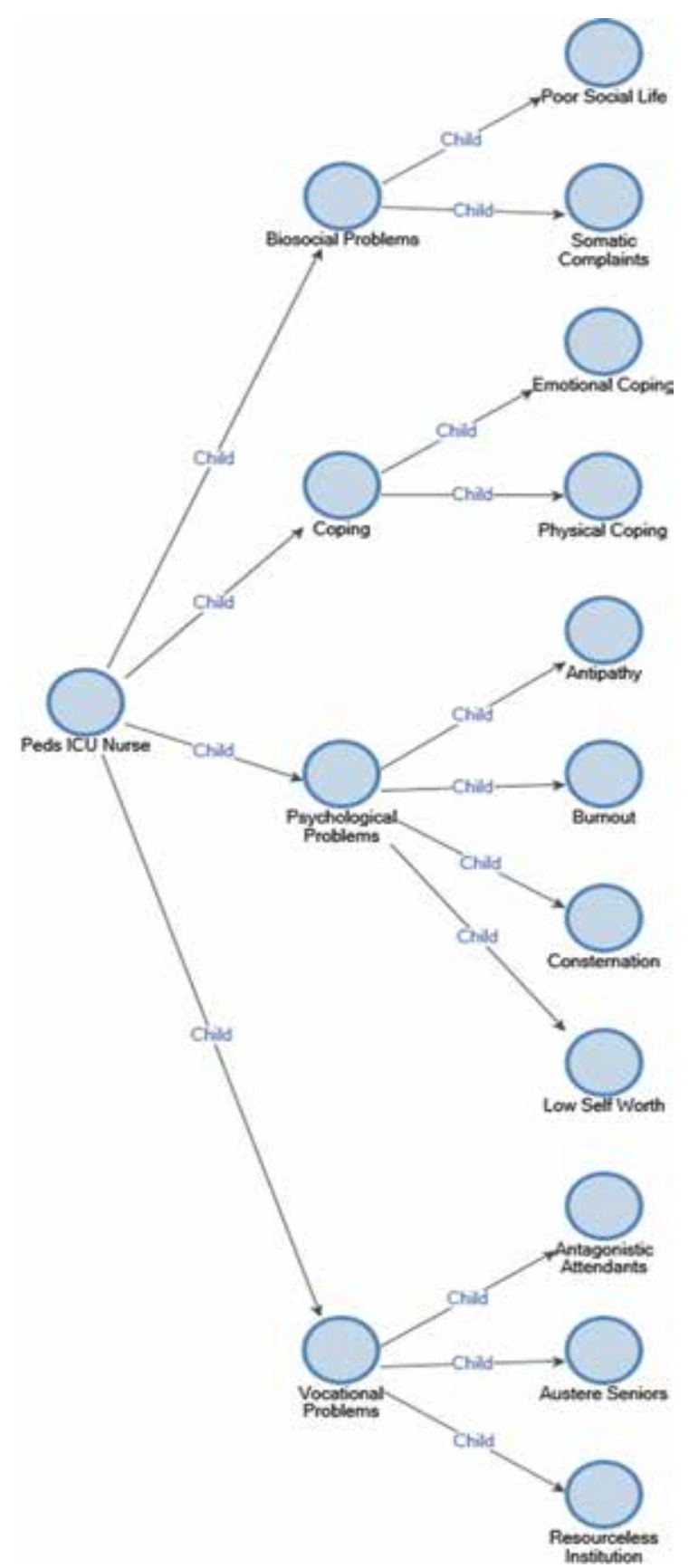

Figure 2: Emerged model of superordinate themes and master themes

nurses in PICU which created difficulty in managing tasks at work and managing life in general. They reported that

"I mean, there is stress, work burden. There is burden... the ICU can be busy anytime. Once it happened that we thought that we were free but a child suddenly became sick and we immediately became busy with him... so there is burden definitely".

"Stress is definitely very high. See if there is shortage of staff it will increase the burden and work load on you".

"Then there are household chores as well and nursing work ... so don't get time for myself. If I have to go somewhere then getting a leave is a problem because you have to manage your work before going or if another nurse has to go then you have to manage her work as well".

Low self-worth: Nurses feel dissatisfied with the care they provide because of the lack of facilities "We have to work with all things that are alternate to the actual things. Basically the care that we have studied and learned is what we try to give but still it's not complete which is not $100 \%$ because of us". It was also reported that when criticized the nurses get confused in the moment in front of everyone and start to doubt their knowledge "Stressful event of mine, hahaha, was a week ago, a patient got sick so our AP starting shouting suddenly. So in such situations even when the person is working, I mean the person gets confused and when there is a senior near you then you know a teacher of ours, you forget what you know. You forget what to do and how to do it. We were managing simultaneously like she was saying we were doing it accordingly. We get a bad image undeniably. The thoughts are like, I can't do this or maybe I don't know how to do this, however I know how to do everything but the time is like that that a person gets confused". Guilt hits the nurses and makes them cry when a child expires "If we feel that something has happened because of us or we could have avoided something before it happened or could save it, even though $50 \%$ the mind tells that it was not our mistake or negligence but still a human has this feeling that maybe we could have done something, you can call it guilt or wish but it happens". The stereotyping of the profession was also raised as a concern "People assume by listening if someone is a nurse that she will be like this or that, bad in speaking and interacting, poor in work etc. It affects personality negatively, obviously in social life when people hear that she is a nurse they are like she will be like that so it shouldn't be like that in my opinion". It was also reported that the confidence gets affected when parents stand too close. Fear of the patient getting sick was also reported "Emotionally, we cry because we do have a heart. If a patient is sick on bed, or expires or if someone scolds saying that you don't know how to work, why did you do it like this, etc.".

Consternation: The nurses have to be on their tip toes at all time because of the emergencies in PICU "We have to be ready all the time. At once there is panic but then we still have to do the work". "Emergency is 24 hours open. They come after being operated and we cannot say that the next half an hour or hour will be absolutely peaceful. There can be emergency anytime". There is unrest and the nurses do not feel relaxed. The concentration gets affected if there is a problem at home "There is a lot of crisis, especially if there is a problem at home, someone is not well then you can't do your work properly. If you are at home then its fine, but on duty you have to see the child, you have to give him injection, the 
concentration gets diverted. There are issues... if there are family problems then you are mentally not set. If someone is unwell at home, then you keep thinking how they are? Whether someone is looking after them? How are they managing? ... then these things change concentration".

\section{VOCATIONAL PROBLEMS}

The superordinate theme of vocational problems was comprised of three master themes namely; antagonistic attendants, austere seniors and resource less institution. Figure 4 depicts the model for the vocational problems theme.

Antagonistic attendants: All of the nurses reported that it is attendants that fail to listen and file complaints against them. They get accused and find themselves in an argument and a fight. "The parents go like "nurse is giving an injection; we don't know what she is giving, she is just a nurse'. They keep asking which medicine is being given. These things are like UHH!..”. "Mothers are sometimes non cooperative, we tell them that there is going to be an operation so that child must not be fed, but they still feed the child and then they say you did not guide well". The attendants were reported to be non-compliant who fail to understand the reasons behind the instructions given by a nurse "They don't understand that we are coming with so many germs to the patient, they say that they are coming to attend the patient". "When we are working and there is a crowd, it messes you up mentally... One by one everybody is allowed to see and come. When there is a crowd all of a sudden then if you favor 1 person then $2^{\text {nd }}, 3^{\text {rd }}$, 4th person... automatically all of them start asking for it". The attendants are rude and file written complaints against nurses even if the attendant is a hospital employee, he or she fails to understand why the nurse is following hospital policies.

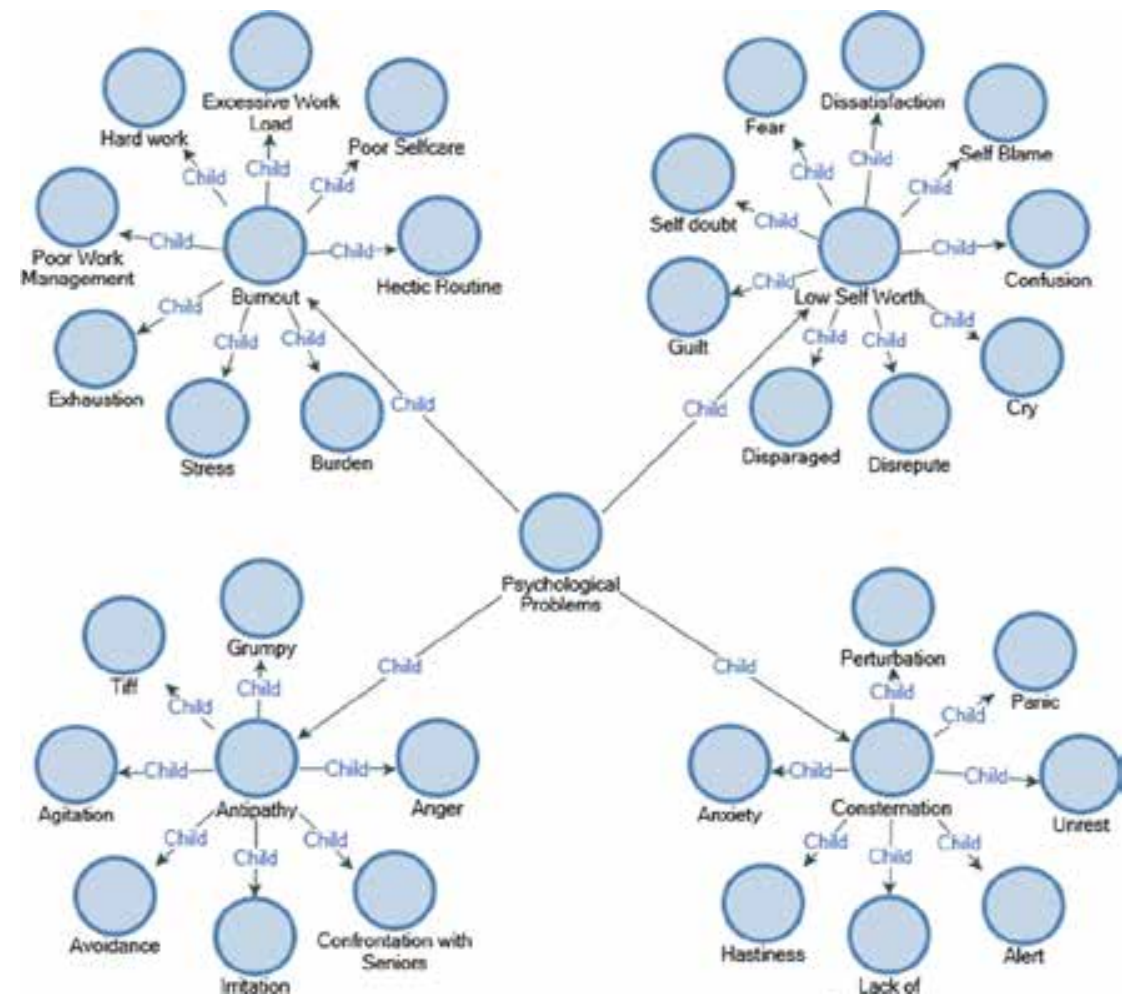

Figure 3: Master themes and subthemes of psychological problems

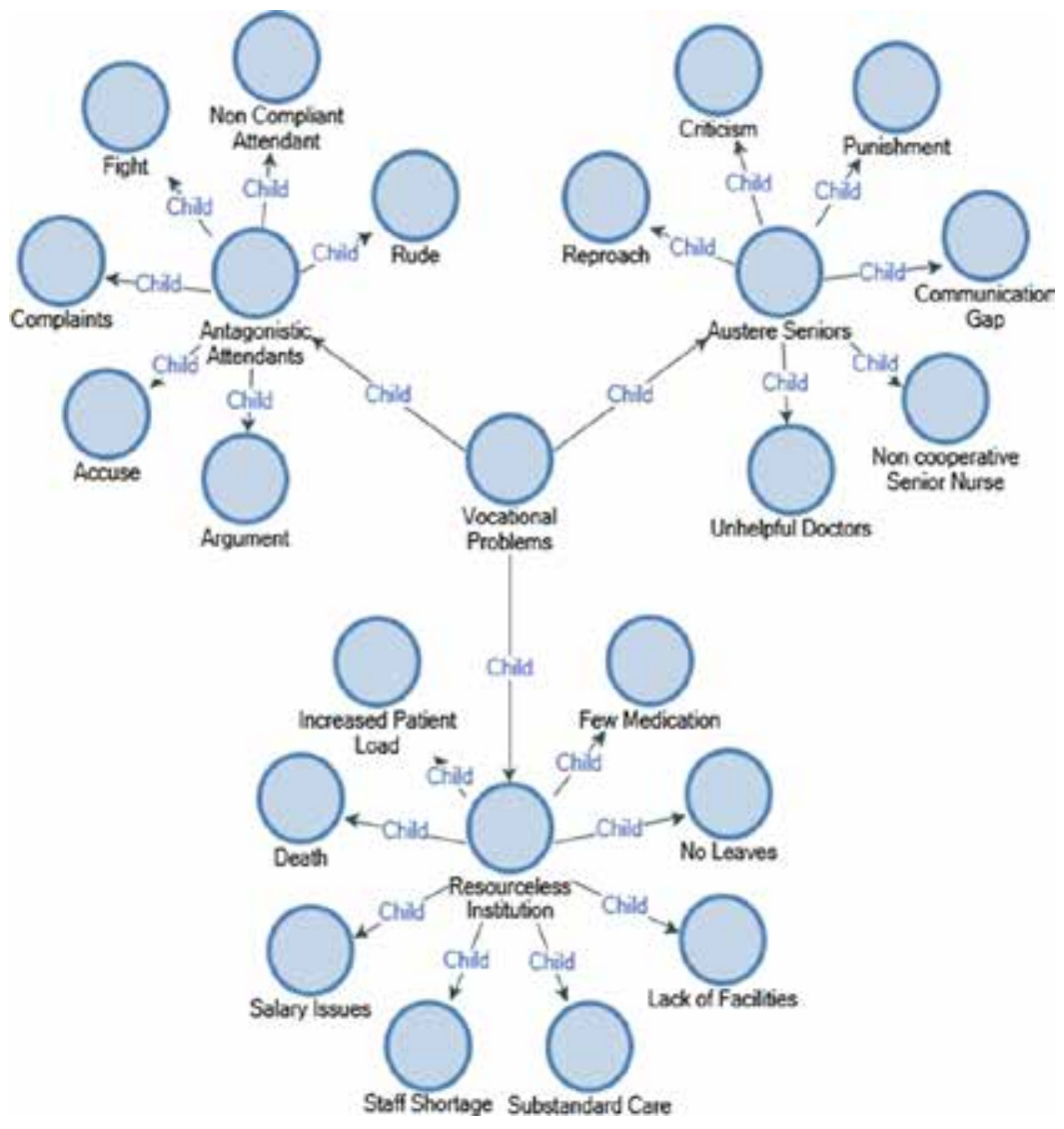

Figure 4: Master themes and subthemes of vocational problems 
Table 1: Master table of themes

\begin{tabular}{|c|c|c|c|c|}
\hline $\begin{array}{c}\text { Superordinate } \\
\text { themes }\end{array}$ & Master themes & & Sub themes & \\
\hline \multirow{12}{*}{$\begin{array}{l}\text { Psychological } \\
\text { Problems }\end{array}$} & \multirow{3}{*}{ Antipathy } & Anger & $\begin{array}{l}\text { Confrontation } \\
\text { with Seniors }\end{array}$ & Irritation \\
\hline & & Grumpy & Tiff & Agitation \\
\hline & & Avoidance & & \\
\hline & \multirow{3}{*}{ Consternation } & Perturbation & Anxiety & Panic \\
\hline & & Hastiness & Alert & Unrest \\
\hline & & Lack of Concentration & & \\
\hline & \multirow{3}{*}{ Burnout } & Stress & Exhaustion & Burden \\
\hline & & Poor Work Management & Hard Work & $\begin{array}{l}\text { Excessive Work } \\
\text { Load }\end{array}$ \\
\hline & & Poor Self-care & Hectic Routine & \\
\hline & \multirow{3}{*}{ Low Self Worth } & Guilt & Self-blame & Self-doubt \\
\hline & & Disrepute & Disparaged & Cry \\
\hline & & Dissatisfaction & Confusion & \\
\hline \multirow{7}{*}{$\begin{array}{l}\text { Vocational } \\
\text { Problems }\end{array}$} & \multirow{3}{*}{$\begin{array}{l}\text { Resource less } \\
\text { Institution }\end{array}$} & Staff Shortage & $\begin{array}{l}\text { Increased } \\
\text { Patient Load }\end{array}$ & Few Medication \\
\hline & & No Leaves & $\begin{array}{l}\text { Substandard } \\
\text { Care }\end{array}$ & Lack of Facilities \\
\hline & & Death & Salary Issues & \\
\hline & \multirow[b]{2}{*}{$\begin{array}{l}\text { Austere } \\
\text { Seniors }\end{array}$} & Punishment & Reproach & Criticism \\
\hline & & Unhelpful Doctors & $\begin{array}{l}\text { Non } \\
\text { cooperative } \\
\text { Senior Nurse }\end{array}$ & $\begin{array}{l}\text { Lack of } \\
\text { Communication }\end{array}$ \\
\hline & \multirow{2}{*}{$\begin{array}{l}\text { Antagonistic } \\
\text { Attendants }\end{array}$} & Complaints & Accuse & Argument \\
\hline & & $\begin{array}{l}\text { Non-compliant } \\
\text { Attendants }\end{array}$ & Rude & Fight \\
\hline \multirow{5}{*}{ Biosocial Problem } & \multirow{4}{*}{$\begin{array}{l}\text { Somatic } \\
\text { Complaints }\end{array}$} & Migraine & Backache & Fever \\
\hline & & Poor Diet & Lethargy & Leg Pain \\
\hline & & Headache & Debilitated & Muscles Pulled \\
\hline & & Fatigue & & \\
\hline & Poor Social Life & No Family Time & $\begin{array}{l}\text { Lack of } \\
\text { Socialization }\end{array}$ & \\
\hline \multirow{3}{*}{ Coping } & $\begin{array}{l}\text { Physical } \\
\text { Coping }\end{array}$ & Take Medicine & Diet Chart & Muscle Relaxant \\
\hline & \multirow{2}{*}{$\begin{array}{l}\text { Emotional } \\
\text { Coping }\end{array}$} & Allah's Will & $\begin{array}{l}\text { Coping } \\
\text { Statements }\end{array}$ & Leisure \\
\hline & & Advice & & \\
\hline
\end{tabular}

Austere seniors: The nurses do not like if their senior nurse favors someone else over them. It was also reported that the doctors criticize publicly and senior nurses scold them in front of patients and their attendants. It was also reported that the nurses are sometimes punished if they make a mistake "Sometimes if things get broken you have to pay from your pocket as punishment. For example, a part gets broken or a glucometer gets broken we have to purchase it or pay fine". "Whether we are talking about attendants or any doctors or any seniors or any public man or anyone, if they try to understand what we are trying to say, for example, if a baby expires then their first point is that child's care was not up to mark. The things which they are explained on time, the messages they are conveyed they don't pick it they don't try to. Even if they are explained a situation as it is, they still think they are right and everyone else is wrong".

Resource less institution: The nurses were concerned about staff shortage and the hospital not providing extra nurses. The lack of facilities e.g., equipment, medications etc. create substandard care for patients. An intensive care unit nurse is also not allowed more than 4 leaves and if a nurse goes on leave the other nurses get the burden of her responsibilities "Because of shortage we have pressure and then we have problems with leaves obviously we have to accommodate everyone, then they cannot facilitate everyone". Apart from salary being late, expiry of a child disturbs the nurses a lot as they either get blamed or extremely sad "The most stressful is that when we are looking after someone a lot and managing them but there is death so it gets very difficult for us and then we cry".

\section{BIOSOCIAL PROBLEMS}

The master themes of biosocial problems were poor social life and somatic complaints. Nurses reported to suffer from backache, lethargy, having poor diet, muscle strain etc. They also mentioned that if they go to emergency to get themselves checked they send them back "We don't get time when we have fever, they don't give us time to rest or go home or give leave. Even when we go in emergency, they just give medicine and say that you don't need rest". "Doctors usually say that nurses just want to stay at home and rest that's why they keep asking for leave but they don't see the burden on nurses, the amount of work they do". The nurses reported that they do not get time to socialize with their friends and 
family a lot. "When you are not physically and mentally okay then you cannot be socially either. The time you have given to your friends or the time you have to spend to go out, you use that time to rest and you want to rest. Instead of spending time outside for entertainment you rather want to finish some work. Often we take some work of the ward home, like expense etc. which is not possible to do on duty".

\section{COPING}

Physically they take medicine for fever or a muscle relaxant and return to work. Some nurses have a diet chart to follow which helps them. "For physical problems we have to take medicine, some muscle relaxant, some take paracetamol for headache and fever, and all that...symptomatic treatment". The nurses also reported that to cope up with the work load they tell themselves that they have to do it anyway "When we come in the morning and we get to know that there are 50 babies in nursery and we are just 4 people and we have to look after all of them then once we get that exposure then we have to prepare ourselves mentally which we do, like if we have to do it then we have to do it one way or the other". Some nurses prefer taking advice from their relatives if they get in a problem with colleagues. Some try to go order food in the hospital and sit with colleagues in their break. Especially when there is death in the PICU, the nurses get disturbed but religious coping helps them out even when they are getting blames for it. It was reported that "Guilty feeling is there that why this happened but then we tell ourselves that it is Allah's will and everyone has to die".

\section{DISCUSSION}

All the PICU nurses were females; this is because in Pakistan the nursing profession is largely considered to be a profession for females only. This gender typing was somewhat addressed in the analysis where the nurses report that being a nurse affects their reputation. The stereotyping of the profession is not the only factor that creates low self-worth; guilt, the self-blame, dissatisfaction etc. also play a role. This finding is consistent with previous researches. ${ }^{6,7}$ Lack of belonging and abandonment are also some of the emotions felt by nurses working in critical care units. $^{8}$

Burnout has been mostly reported by the nurses to be a problem. According to Crowe et al., grief and burnout in the nurses can lead to psychological problems which if left untreated may hamper their ability to work in a competent and compassionate manner. ${ }^{6}$ The problems PICU nurses face at work are numerous including criticism, complaints, lack of facilities, staff shortage etc. Wheeler et al. ${ }^{4}$ also suggest that staffing and work force issues in PICU

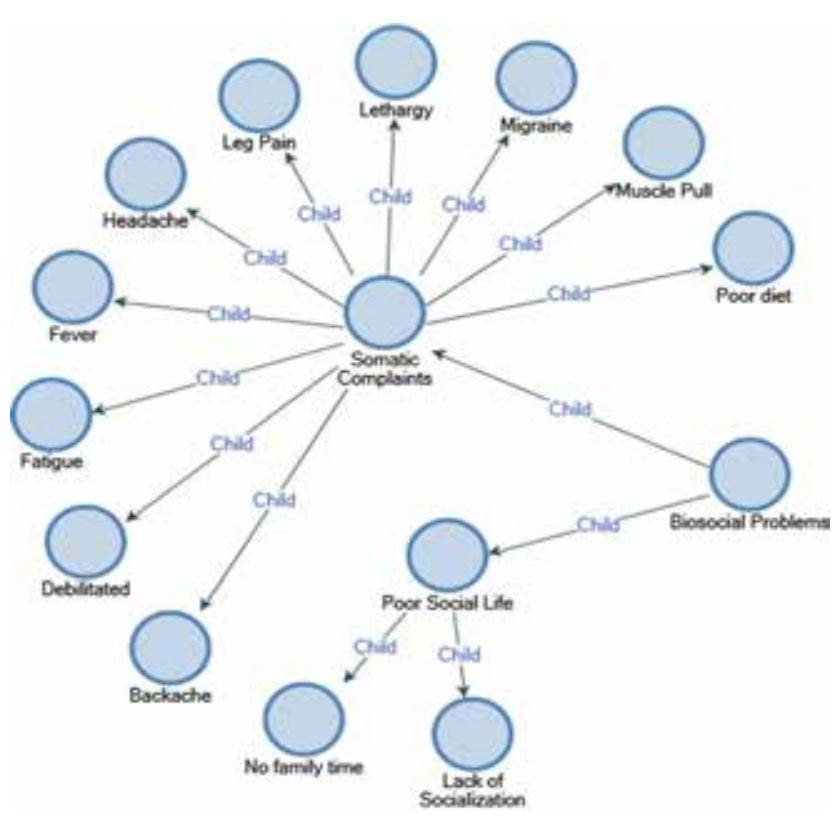

Figure 5: Master themes and subthemes of biosocial problems

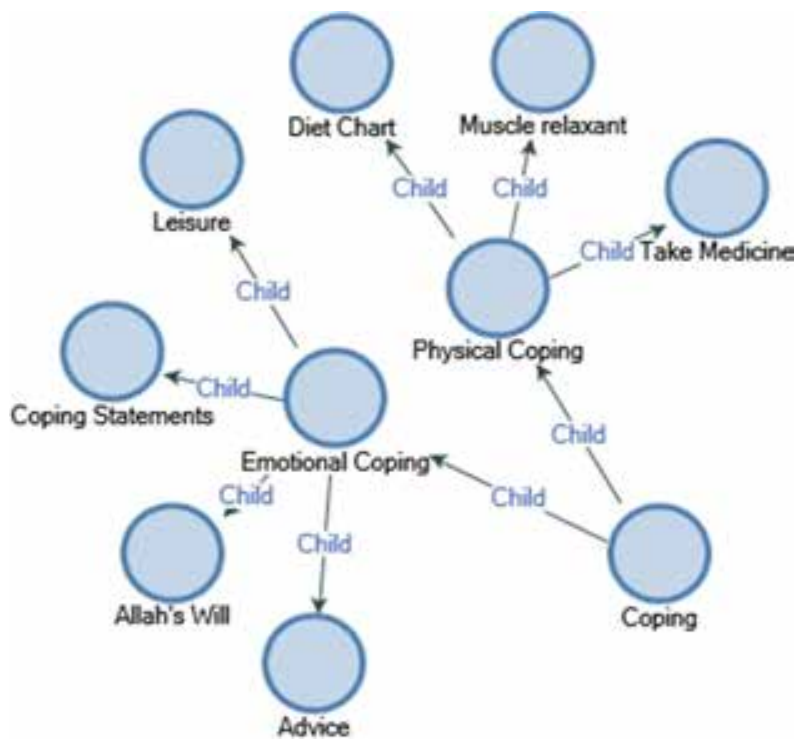

Figure 6: Master themes and subthemes of coping

if addressed can improve the value of care delivered in the PICU. The nurses had reported that those higher in hierarchy than them including doctors and senior nurses were unhelpful, non-cooperative and austere. Nurses in critical care units receive nonsupport from the management and medical doctors. ${ }^{9}$ Some researchers concluded in their study by stating that nurses felt "abandoned, rejected or ignored' when they asked assistance from medical doctors. ${ }^{10,11}$ Participants described instances where physicians, not present in the unit, disagreed with the nurses about their assessment of a patient, stating that the nurses were wrong.

Nurses reported to have many physical problems such 
as headache, backache, leg pain by standing too much, lethargy etc. Similar findings were reported by Jones, Hocine, Salomon, Dab Temime (2015) ${ }^{12}$, in which current state of nurses was fatigue and tiredness. The burden of work makes the nurses unable to enjoy their social life. They are unable to give time to themselves, family or friends. The nurses prefer resting instead of going out. Studies show that the lack of socialization of nurses hinders the desirable and high quality nursing cares. ${ }^{13}$ Socialization within the profession can lead to self-development in nurses, increase the durability of a person in the relevant profession and increase job satisfaction. ${ }^{14,15,16}$

PICU nurses cope up with physical problems by taking medication or following a diet plan yet for emotional and psychological problems they practice religious coping. Reminding themselves that everything is in Allah's hand and a death of a child is not their fault even if they are blamed for it helps the nurses cope from such a stress. God is considered as a safe haven in emotionally stressful situations. ${ }^{17}$ Action oriented coping included getting advice from close ones and using coping statements to survive stressful situations. Jones et al. reported that social support decreased stress and fatigue in nurses working intensive care units. ${ }^{12}$ Nurses are expected to keep on working even after the death of a patient which makes them emotionally disconnected. This might be by choice or even a subconscious skill that had developed over time. Work related stress when communicated with family or colleagues also helped the nurses. ${ }^{9}$

No attempt is made to generalize these results. Five nurses were included in the study; phenomenology studies have been conducted with one, three, four, nine, and 15 or more participants. ${ }^{18}$

\section{LIMITATIONS AND SUGGESTIONS}

The researcher faced a great deal of difficulty in approaching the nurses due to the ongoing strike of doctors and hospital staff in the country. It is recommended to conduct a similar project some other time of the year with increased number of participants to explore experiences in depth. Only the nurses of public sector hospitals were approached, it is recommended to conduct in depth study with those working in a private facility so that a comparison can be made.

\section{IMPLICATIONS}

The results of this study can help psychologists to make management plans for PICU nurses who can help to maintain their competence and compassionate nature for patients and attendants. The results of this study can help to facilitate the nurses by providing more resources. The hospital may hire social workers in every PICU who can counsel the attendants and work out their problems as it is difficult for nurses to provide emotional nourishment and medical treatment simultaneously. It is required that the nurses are not burdened in their training and provided a comfortable working environment.

\section{CONCLUSION}

It is established that the PICU nurses face problems that are different from other hospital personnel. The death of the child, staff shortage, stress, burden of work, constant criticism and complaints wear them down emotionally and physically. The PICU nurses have found ways to cope with their hectic and physically and emotionally draining routine.

Conflict of Interest: Authors declare no conflict of interest.

Authors' contribution:

LZ - Conducted the study, data search, manuscript writing

MR - Study idea, supervision of the project 
original research

\section{REFERENCES}

1. Islam A. Health sector reform in Pakistan: why is it needed? JPMA. 2002;52(3):95-100. [Free Full Text]

2. Huda S, Alisbinati SA. Nursing education in Pakistan: challenges and trends in degree program. Int J Nurs Edu. 2015;7(4):59-62. [Free Full Text]

3. Kumar A, Pore P, Gupta S, Wani AO. Level of stress and its determinants among intensive care unit staff. Indian J Occup Environ Med. 2016 SepDec;20(3):129-32. [PubMed] DOI: 10.4103/0019-5278.203137

4. Wheeler DS, Dewan M, Maxwell A, Riley CL, Stalets EL. Staffing and workforce issues in the pediatric intensive care unit. Transl pediatr. 2018 0ct;7(4):275-83. [PubMed] DOl: $10.21037 /$ tp.2018.09.05

5. Doorenbos A, Lindhorst $T$, Starks $H$, Aisenberg E, Curtis JR, Hays R. Palliative care in the pediatric ICU: challenges and opportunities for family-centered practice. J Soc Work End Life Palliat Care. 2012 Dec 1;8(4):297-315. [PubMed] DOI: 10.1080/15524256.2012.732461

6. Crowe $S$, Sullivant S, Miller-Smith L, Lantos JD. Grief and burnout in the PICU. Pediatrics. 2017 May 1;139(5):e20164041. DOI: 10.1542/ peds.2016-4041

7. Evans J, Bell JL, Sweeney AE, Morgan
JI, Kelly HM. Confidence in critical care nursing. Nurs Sci Q. 2010 Oct;23(4):334-40. [PubMed] DOI: $\underline{10.1177 / 0894318410380253}$

8. Stievano A, Marinis MG, Russo MT, Rocco G, Alvaro R. Professional dignity in nursing in clinical and community workplaces. Nurs Ethics. 2012 May;19(3):341-56. [PubMed] DOI: $10.1177 / 0969733011414966$

9. Scholtz S, Nel EW, Poggenpoel M, Myburgh CP. The culture of nurses in a critical care unit. Glob Qual Nurs Res. 2016;3:2333393615625996. [PubMed] DOI: 10.1177/2333393615625996

10. Stein-Parbury J, Liaschenko J. Understanding collaboration between nurses and physicians as knowledge at work. Am J Crit Care. 2007 Sep 1;16(5):470-7. [PubMed]

11. Hughes LC. Bridging the gap between problem recognition and treatment: the use of proactive work behaviors by experienced critical care nurses. Policy Polit Nurs Pract. 2012 Feb;13(1):54-63. [PubMed] DOI: $10.1177 / 1527154412443286$

12. Jones G, Hocine M, Salomon J, Dab W, Temime L. Demographic and occupational predictors of stress and fatigue in French intensive-care registered nurses and nurses' aides: a cross-sectional study. Int J Nurs Stud. 2015 Jan 1;52(1):250-9. [ㄹuMed] DOI: 10.1016/j.ijnurstu.2014.07.015

13. FarsiZ, Dehghan-Nayeri N, Negarandeh $\mathrm{R}$, Broomand $\mathrm{S}$. Nursing profession in Iran: an overview of opportunities and challenges. Jpn J Nurs Sci. 2010 Jun;7(1):9-18. [PubMed] DOl: 10.1111/j.1742-7924.2010.00137.x

14. Lai PK, Lim PH. Concept of professional socialization in nursing. Int e-Journal Sci Med Ed. 2012 Jan 1;6(1):31-5. [Free Full Text]

15. Ryynänen K. Constructing physician's professional identity: explorations of students' critical experiences in medical education. Oulun yliopisto; 2001. [Free Full Text]

16. Mbambo MS. The relationship between professional socialisation and job satisfaction of nurse educators of a provincial nursing college in South Africa. Available from: https://repository.nwu.ac.za/ handle/10394/10763

17. Mikulincer M, Shaver PR. Attachment in adulthood: structure, dynamics, and change. Guilford Press; 2007 May 14. [Free Full Text]

18. Smith J. A, Flowers P, Larkin M. Interpretative phenomenological analysis: theory, method and research. London: Sage; 2009. 